University of Nebraska - Lincoln

DigitalCommons@University of Nebraska - Lincoln

To Google or Not to Google: Graduate Students' Use of the Internet to Access Personal Information about Clients

David K. DiLillo

University of Nebraska-Lincoln, ddilillo@unl.edu

Emily B. Gale

University of Nebraska-Lincoln

Follow this and additional works at: https://digitalcommons.unl.edu/psychfacpub

Part of the Psychiatry and Psychology Commons

DiLillo, David K. and Gale, Emily B., "To Google or Not to Google: Graduate Students' Use of the Internet to Access Personal Information about Clients" (2011). Faculty Publications, Department of Psychology. 556. https://digitalcommons.unl.edu/psychfacpub/556

This Article is brought to you for free and open access by the Psychology, Department of at DigitalCommons@University of Nebraska - Lincoln. It has been accepted for inclusion in Faculty Publications, Department of Psychology by an authorized administrator of DigitalCommons@University of Nebraska - Lincoln. 
Published in Training and Education in Professional Psychology (2011) 5(3): 160-166. Copyright 2011, American Psychological Association. DOI: $10.1037 /$ a0024441. This is an authors' copy, not the copy of record. Used by permission.

\title{
To Google or Not to Google: Graduate Students' Use of the Internet to Access Personal Information about Clients
}

\author{
David DiLillo and Emily B. Gale \\ Department of Psychology, University of Nebraska-Lincoln, Lincoln, Nebraska, USA
}

\begin{abstract}
The emergence of Internet search and social media sites now permits therapists to obtain a plethora of personal information about their clients online. These behaviors raise a number of ethical issues related to client privacy, self-determination, and informed consent. The purpose of this study is to examine student therapists' opinions and behaviors in regard to the use these websites to search for information about their clients. A national sample of 854 psychology doctoral students was surveyed in regard to their online activities, attitudes, and frequency of searching for client information online. Results showed that Internet usage is pervasive in this group, with the majority reporting daily use of search engine or social networking sites. Most participants reported that searching for information about clients online using search engines (66.9\%) or social networking websites (76.8\%) was "always" or "usually" unacceptable. Nevertheless, $97.8 \%$ of participants reported searching for at least one client's information using search engines in the past year; $94.4 \%$ reported searching for client information on social networking websites. Overall, student therapists reported searching for $16.5 \%$ of clients seen in the past year, using either search engine or social networking sites. The ethical and training implications of these results are discussed.
\end{abstract}

Keywords: Internet, Privacy, Social media, Training, Ethics

The explosion of search engine and social networking websites now permits anyone with an Internet connection to view a plethora of personal information about others. Through these sites, information that was previously private, or at least more difficult to obtain, is now easily available to the public with the simple click of a mouse. Personal information, including photographs, videos, criminal records, credit reports, property values, political or religious affiliations, and other data are now potentially accessible online. This unprecedented access raises a range of new questions about how Internet search and social networking capabilities impact the training of professional psychologists. For example, recent writings have discussed the ethical implications of faculty members using the Internet to search for graduate school applicants or current students, as well as the possibility of clients accessing detailed personal information about student therapists online (Lehavot, 2009). In addition to these situations that may leave students vulnera-

\footnotetext{
David D. DiLillo, Ph.D., is Professor and Director of Clinical Training at the University of Nebraska-Lincoln. His primary research interests lie in the areas of child maltreatment and interpersonal violence. He also maintains a scholarly interest in issues related to education and training in professional psychology. Corresponding author: ddilillo2@unl.edu.

Emily B. Gale, M.A., is a fifth-year student in the Clinical Psychology Training Program at the University of Nebraska-Lincoln. Her primary interests are ethical issues related to the Internet, training in psychology and child maltreatment.
}

Article history: received September 1, 2009; revision received March 7, 2011; accepted March 29, 2011. ble to searches, there is also potential for trainees - many of whom are likely to be well versed in search and social media websites - to seek information about others online, including their clients. Whether it is to verify facts provided by the client, to obtain information perceived to be clinically relevant, or just out of curiosity, the types of information that can be accessed by therapists about clients are virtually limitless. The vast amount of personal information online raises the important question of whether it is ethically appropriate for practitioners, including student trainees, to search for information about clients using the Internet. The current Ethical Principles of Psychologists and Code of Conduct (American Psychological Association, 2002), which came into existence before widespread use of the Internet as a source of personal information, provides little explicit guidance in addressing Internet searches. Nevertheless, General Principle E states that, "Psychologists respect the dignity and worth of all people, and the rights of individuals to privacy, confidentiality, and self-determination" (p. 1063). In commenting on client privacy, Smith-Bell and Winslade (1999) noted that, "when a person enters into a therapeutic relationship, the client relinquishes his or her personal privacy of thoughts, feelings, beliefs, and so forth, in exchange for the prospect of therapeutic understanding and assistance" (p. 152). Implied in this arrangement is an understanding that the client determines the type and timing of personal information to be disclosed to the therapist. Although various factors may influence these decisions (e.g., length of time in therapy; strength of the therapeutic alliance; Farber, 2003), few would dispute that a client's right to privacy includes deciding if and when to share personal information with a therapist. A corollary to this is that therapists do not actively seek information about clients through outside channels without a client's knowl- 
edge. Indeed, doing so (e.g., through an online search) may be viewed as an unauthorized intrusion of privacy that undermines a client's right to self-determination alluded to in Principle E.

As suggested above, a key element in evaluating whether a search violates a client's privacy is the question of prior approval. Standard 3.10a requires that therapists seek informed consent from clients about the services to be provided. Although commonly known to involve certain components (e.g., discussing confidentiality and its limits, fees and payment options, the training status of student therapists), informed consent also encompasses a broader need to inform clients about the nature and process of psychotherapy, including approaches and techniques that might be used (Fisher \& Oransky, 2008). Thus, just as therapists must secure written authorization to obtain information about clients from third parties (e.g., prior therapists, physicians; Fisher, 2002), so too should they request permission before accessing sources such as the Internet. Failure to do so places therapists in the difficult position of deciding how to use newly acquired information therapeutically without clients feeling their privacy has been violated.

Although the need for privacy and informed consent suggest that therapists' use of the Internet to search for clients may be inappropriate, graduate students' views and actual behaviors in this emerging area are currently unknown. Consistent with the above discussion, many trainees may feel that clients should be the sole gatekeepers of information about themselves - and that accessing personal information online (i.e., by "Googling") without a client's permission is a violation of privacy that could damage the therapeutic relationship. On the other hand, many student therapists, for whom Internet search and social networking activities are commonplace in everyday life, may see little harm in conducting searches. According to this view, information on the Internet is publicly available and represents an appropriate and, at times, therapeutically useful source of information about clients (e.g., to check for prior sex offenses committed by a client). This viewpoint would be consistent with the observation that social media and other websites have contributed to an erosion of interpersonal boundaries and decreased expectations of privacy between individuals (Behnke, 2008). These differing positions represent two of the many opinions that trainees may hold about conducting searches for clients on the Internet. Mirroring these opinions may also be differences in actual searching behaviors, with some trainees having refrained from searches altogether while others perhaps searching for many clients. Despite anecdotal reports that mental health providers routinely turn to the Internet as a source of information about clients (Clinton, Silverman, \& Brendel, 2010), it appears that no published research has examined therapists' attitudes or actual use of the Internet in this manner.

The overarching purpose of this study is to examine doctoral trainees' opinions and behaviors about online searches for information about their clients. The recent emergence of these issues called for an exploratory investigation of several important questions, which we conducted with a large sample of clinical, counseling, and school psychology doctoral students. The specific aims of the study were to do the following:
1. Assess graduate students' attitudes regarding the acceptability of using search engine and social networking websites to search for personal information about their clients. Although the lack of prior work in this area makes predictions about overall acceptability difficult, findings that younger individuals are more frequent users of Internet (Jones, 2002) suggest that, relative to older respondents, younger participants will find such searches more acceptable. Further, as time in program increases - and students presumably receive more formal ethics training and real-world clinical experience-we expected that the acceptability of searching for clients would decline.

2. Document the frequency with which trainees use search engines and social networking sites to seek personal information about clients. Corresponding to our predictions about attitudes, we expected that younger participants and those earlier in training would more frequently engage in these behaviors.

3. Finally, because of the ethical relevance of informed consent in conducting Internet searches, we also assessed whether student therapists inform clients of their attempts to locate personal information about them online.

Method

Participants

Participants were 854 students enrolled in clinical, counseling, and school psychology doctoral programs in the United States and Canada. Participants resided in 43 different states as well as several cities in Canada. The mean age of participants was $28.07(\mathrm{SD}=4.92)$ years. Participants were mostly female (81.5\%), European American (89.9\%), and non-Hispanic $(93.8 \%$; see Table 1 for full demographic characteristics of the sample). These sample characteristics are comparable to national data reported to APA by Accredited Doctoral Programs in the United States in 2008 (www.apa.org, retrieved March 16th, 2010). The majority of participants were doctoral-level students $(88.8 \%)$ and were enrolled in clinical psychology programs $(68.4 \%)$, followed by counseling $(15.9 \%)$ and school (15.8\%) psychology doctoral programs. ${ }^{1}$

\section{Measures}

Internet usage questionnaire. This questionnaire was designed by the investigators to collect data relevant to the primary study aims (see Table 2 for item wording and response options). To establish baseline usage rates, participants initially reported their overall use of search engines and social networking sites for any purpose, as well as whether they maintained a personal webpage on a social networking site. Participants then responded to Likert-type items, assessing (a) attitudes about the acceptability of therapists who use search

\footnotetext{
${ }^{1}$ The survey was distributed only to doctoral programs. However, in response to Item 5 (simply stated "Degree type") some participants selected the option "terminal masters" (see Table 1). All individuals who selected "terminal masters" nevertheless reported that they were currently in their third or fourth year of training, which is inconsistent with being in a master's program. We conclude that these respondents were doctoral students who reported their highest degree earned to date (the masters).
} 
Table 1

Sample Characteristics $(N=854)$

\begin{tabular}{lc}
\hline \multicolumn{1}{c}{ Variable } & Univariate statistic \\
\hline Age & $28.07(4.92)$ \\
Gender & \\
Male & $152(18.5 \%)$ \\
Female & $668(81.5 \%)$ \\
& \\
Race-Ethnicity & $693(89.9 \%)$ \\
White-European American & $44(5.7 \%)$ \\
Asian & $27(3.5 \%)$ \\
Black-African American & $7(.9 \%)$ \\
American Indian-Native Alaskan & \\
Hispanic & $51(6.2 \%)$ \\
Yes & $769(93.8 \%)$ \\
No & \\
& \\
Degree type & $690(88.8 \%)$ \\
PhD & $40(5.1 \%)$ \\
PsyD & $46(5.9 \%)$ \\
Terminal MA & \\
Program type & \\
Clinical & $560(68.3 \%)$ \\
Counseling & $130(15.9 \%)$ \\
School & $130(15.9 \%)$ \\
Year in program & \\
1st & $160(19.4 \%)$ \\
2nd & $153(18.6 \%)$ \\
3rd & $166(20.1 \%)$ \\
4th & $140(17.0 \%)$ \\
5th & \\
6th and beyond & \\
\hline
\end{tabular}

Note. $\mathrm{PhD}=$ doctorate; $\mathrm{PsyD}=$ doctor of psychology; MA = master of arts.

engines and social networking sites to seek information about clients, as well as their actual searching behaviors; and (b) clients' awareness (or not) of such behaviors. Following the item-assessing acceptability of searching, an openended question asked participants to provide the rationale for their response. Because the information available through search engines and social networking sites can differ, participants were queried separately for each type of site.

\section{Procedures}

Following approval from the Institutional Review Board, solicitation for participants proceeded in two ways. First, to contact clinical and school psychology students, individual recruitment e-mails were sent to the training directors (TDs) of APAaccredited clinical and school psychology programs in the United States and Canada. TDs' e-mail addresses were obtained through the websites of the Council of University Directors of Clinical Psychology (CUDCP; 187 member programs) and the National Association of School Psychology (NASP; 89 member programs). A recruitment e-mail that contained a brief description of the study was sent to TDs with a request for them to forward the survey link to their students. To contact counseling psychology TDs, the same study description and link was posted to the counseling psychology
TDs' listserv, with a request that they forward the recruitment e-mail to their students. Interested participants were directed to a Survey Monkey website, where they gave consent to participate before completing the questionnaire. As incentive for completing the questionnaire, participants were offered the opportunity to enter a drawing for one of three $\$ 50$ cash awards. The completion rate for this study (percentage of those viewing the survey who finished it) was $91.3 \%$.

Results

Overall Use of Search Engines and Social Networking Sites The distribution of responses to items on the Internet usage questionnaire is contained in Table 2. Overall, $87.6 \%(n=$ 684 ) of respondents reported using search engines on a daily basis, whereas $30.9 \%(n=242)$ reported daily usage of social networking sites. In addition, $71.8 \%(n=562)$ reported having a personal webpage on social networking websites such as Facebook or MySpace.

Acceptability of Searching for Client Information

Approximately $67 \%(n=522)$ of participants felt it was either never acceptable or usually not acceptable to search for information about a client by using search engines. Because age and year in program were positively correlated, $r(820)$ $=0.36, p<0.001$, partial correlations were used to examine associations between these two variables and acceptability ratings with the effects of the other variable removed. Contrary to expectations, there was no significant correlation between age and acceptability of searching for a client by using a search engine. Also unexpectedly, a positive partial correlation was found between year in program and acceptability of searching for client information using a search engine, $r(773)=0.12, p=0.001$.

For social networking websites, $76.8 \%(n=598)$ of the sample felt it was either never acceptable or usually not acceptable to search for client information. Contrary to prediction, a partial correlation controlling for year in program showed no relationship between age and acceptability of searching for a client on a social networking website. Also unexpectedly, a small but significant positive correlation was found between year in program and acceptability of searching for client information on social networking websites, $r(773)=0.09, p=0.007$.

Figure 1 contains a summary of open-ended responses that reflect the reasons why it might be acceptable to search for a client's information online. These responses were coded by the second author for content, with a number of categories emerging. Although the most common response overall was that it was not acceptable under any circumstances to search for a client's information online, the most common reason searching was seen as acceptable was to assess client risk. Chi-square analyses were used to test differences between the frequencies of reasons provided for conducting search engine and social networking searches. Proportionally more respondents found it unacceptable to search for client information on social networking websites compared to search engines $(40.0 \%$ for search engines; $47.2 \%$ for social networking websites), $X^{2}(10, N=778)=17.11, p<0.01$. Significantly more respondents also indicated that client consent was needed before conducting a search on a social networking website $(38.8 \%)$ than a search engines $(26.4 \%), X^{2}(10, N=570)=20.0$, $p<0.05$. Similarly, a larger proportion of respondents said 
Table 2

Summary of Internet Usage for All Participants

\section{Variable}

Univariate statistics

Frequency of Google usage:

Never

Less than once every two months

$2(0.3 \%)$

Once per month

$2(0.3 \%)$

Once per week

Daily

Frequency of Facebook, MySpace, or other social networking website usage:

Never

$173(22.1 \%)$

Less than once every two months

$94(12.0 \%)$

Once per month

$82(10.5 \%)$

Once per week

$192(24.5 \%)$

Daily

$243(31.0 \%)$

Do you have a profile on a social networking website?

Yes $563(71.8 \%)$

No $221(28.2 \%)$

How do you rate the acceptability of searching for information about a client using Google?

Never acceptable

$214(27.4 \%)$

Usually not acceptable

$309(39.6 \%)$

Sometimes acceptable

$164(21.0 \%)$

Often acceptable

Always acceptable

How do you rate the acceptability of searching for information about a client on social networking websites such as Facebook or MySpace?

Never acceptable

Usually not acceptable

$328(42.1 \%)$

Sometimes acceptable

$271(34.7 \%)$

Often acceptable

$121(15.5 \%)$

Always acceptable

$23(2.9 \%)$

that using search engines was acceptable to confirm client reports given in therapy $(11.7 \%$ for search engines compared to $2.6 \%$ for social networking sites; $X^{2}(10, N=563)=26.74, p$ $<0.01$. Differences were also found for searching for general information about clients, with more participants indicating this is an acceptable use of search engine $(18.4 \%)$ than social networking website use $(3.2 \%), X^{2}(10, N=563)=36.98$,

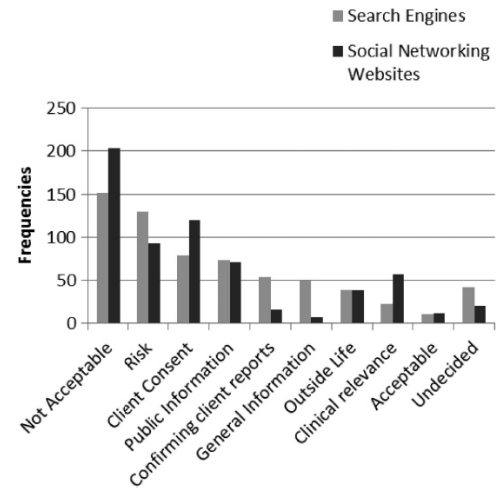

Figure 1. Reasons for searching for clients who use search engine and social networking websites. $p<0.01$. Finally, seeking personal websites that may be relevant to topics discussed in session was more often offered as a reason for searching social networking websites $(26.6 \%)$ than search engines $(11.8 \%), X^{2}(10, N=571)=50.26, p<0.01$.

Seeking Information About Clients

The total sample of 854 participants reported seeing 13,582 therapy or assessment clients in the past year $(M=15.9$ per student). These respondents reported having searched the Internet for $16.5 \%$ of all clients $(n=2,241)$ using either search engine or social networking sites. Of the 783 participants who reported seeing clients, $97.8 \%(n=766)$ had searched for at least one client's information using search engines such as Google, whereas $94.4 \%(n=739$ had searched for at least one client's information using social networking websites. It is interesting to note that $66.9 \%(n=513)$ of those therapists who had conducted search engine searches for client information also reported that it was either always or usually unacceptable to do so. Likewise, $76.8 \%(n=568)$ of those therapists found it always or usually unacceptable to search for client information on social networking websites.

Partial correlations were again used to examine the relationships between age and year in program in relation 
to percentage of clients searched by using search engines and social networking sites. Contrary to predictions, there was no relationship between age and percentage of clients searched by using either search engines or social networking websites, while controlling for year in program. As predicted, however, a significant negative relationship emerged for year in program and the percentage of clients searched by using search engines, while controlling for age, $r(733)=-$ $0.28, p<0.001$. A significant negative association was also found between year in program and the percentage of clients searched by using social networking websites, after controlling for age, $r(733)=-0.26, p<0.001$.

\section{Client Knowledge of Searches}

As mentioned previously, $97.8 \%$ of therapists had searched for at least one client using search engines such as Google, and $94.4 \%$ had searched for at least one client using social networking websites. The nearly universal reports of having searched for client information raise the question of whether clients are aware of these activities on the part of their therapists. Among those who had searched for at least one client, therapists reported that $82.1 \%(n=643)$ of those clients were aware of the Google search, whereas $82.5 \%(n=646)$ of clients were said to have been aware of their therapists social networking search.

\section{Discussion}

This study may be the first to assess therapists' attitudes and actual attempts to use the Internet to obtain personal information about clients. Most participants (67\%) found it completely unacceptable or usually not acceptable to search for client information online. Although these findings indicate that therapists primarily disapprove of using the Internet as a source of information about clients, nearly all participants had searched for at least one client by using search engine or social networking sites (97.8\% and $94.4 \%$, respectively). Moreover, two thirds of these participants who disapproved of searches had nonetheless conducted at least one search for information about a client. This discrepancy between attitudes and actual behaviors should be considered in the context of graduate students' overall frequent use of Internet search and social media sites. Here, the majority of respondents reported using one or both of these sites on a daily basis, and over $75 \%$ maintained their own social networking pages. These findings demonstrate that search and social networking activities are commonplace in trainees' everyday lives. Thus, just as doctoral students may think nothing of taking a few moments to learn something about a new social acquaintance online, so too may they quickly turn to the Internet as a source of information about their clients. Responding to survey questions about these activities, however, may have given participants reason to pause and more carefully consider the appropriateness of these activities, leading most to express hesitation about conducting such searches. Nevertheless, the reported discrepancy between attitudes and actual search behaviors suggests that although trainees recognize that searches are ethically questionable, the ubiquity of these activities in their everyday lives may lead them to feel that client searches are of little consequence or are easily justified because of their anonymity (e.g., "What my client doesn't know won't hurt him/ her"). If so, this suggests a need for education efforts that heighten trainees' awareness of the ethical implications of online searches in order to bring behaviors more in line with their cautious attitudes about such practices.

Contrary to expectations, no unique associations were found between age and either attitudes about client searches or actual search behaviors. Perhaps exposure to the culture of the Internet, including the pervasive use of search and social networking sites, has resulted in a similarity of attitudes and behaviors within the relatively narrow age range of participants in this study. As expected, we found a relationship between year in program and search behaviors, such that more advanced training was associated with fewer clients searched. These results are encouraging and suggest that with increasing experience and professional development, students are less likely to engage in client searches, presumably due to greater cognizance of the ethical and therapeutic issues involved. At the same time, however, we found positive associations between year in program and the acceptability of conducting client searches. Although significant, these associations were rather weak (0.09 and 0.12 for search engines and social networking sites, respectively).

Nearly all graduate student therapists had used search engine or social networking sites to search for at least one client's information. Student therapists, therefore, are actively seeking information about certain clients through means other than face-to-face conversations or traditional requests for records from third parties. At the same time, therapists are not searching indiscriminately for every client online $(16.5 \%$ of all clients had been searched), which suggests that trainees are using criteria in making decisions about which client's information to search for online. The responses to the open-ended questions shed light on this reasoning. The most common reasons for searching included (a) gaining a better understanding of the client's outside life, (b) clarifying personal information such as phone numbers or addresses, and (c) investigating issues that arose in therapy (i.e., risk issues or confirming questionable client reports). These findings suggest that a wide range of justifications are being used for conducting searches. Further, differential criteria were offered for using search engine versus social networking sites. Search engines were more likely to be used in cases of fact checking client reports. Notably, issues that concern clinical relevance were more likely to trigger searches on social networking websites than search engines. This finding suggests that therapists may view these websites as useful sources of clinically relevant information such as self-harm or substance abuse behaviors. These findings indicate that therapists are determining which website will best provide the type of information they are seeking about their client.

Surprisingly, trainees reported that the vast majority of clients $(82.1 \%)$ were aware of the searches they had conducted. This finding is encouraging and consistent with the openended reports that obtaining client consent is an important consideration in determining whether to conduct a search, particularly on social networking sites. These results also suggest broad support for the notion that searches should not be conducted without client knowledge and informed consent. However, many questions remain about the means by which clients are informed about these searches. For example, do therapists obtain consent from clients prior to con- 
ducting a search or do clients find out only after searches have taken place? Are clients inviting therapists to "friend" them on social networking sites, thus granting them permission to search? Given the importance of obtaining informed consent, further investigation is needed to explore how and when these conversations are taking place. Finally, we cannot rule out the possibility that the high rates of informing clients about searches found here partially reflect over reporting by therapists who are hesitant to disclose searches were conducted without clients' knowledge.

Clearly, some trainees are turning to the Internet as a source of information about clients, and believe that doing so is acceptable for a variety of reasons. This suggests a need for clear principles to guide clinicians in deciding the circumstances in which searches can be conducted ethically and in the best interest of clients (e.g., without unnecessary breaches of privacy). For example, most would agree that searching online for a client's contact information is not ethically problematic; however, searching for other information should be guided by more explicit ethical guidelines. As noted, although certain aspects of the current APA Ethics Code are relevant, the current version was developed before the emergence of the Internet as a major source of personal information. We invite APA to consider offering more explicit guidance, or to provide further advice for extrapolating current principles to online searches (see Behnke, 2010). For example, Clinton et al. (2010) offered a heuristic framework for making ethical decisions about the appropriateness of client searches. This framework stresses a case-by-case consideration of (a) the reason for conducting a search, (b) the positive or adverse effects of a search on treatment, (c) the question of obtaining client consent, (d) whether to share results of the search with the client, and (e) whether to document the search. Efforts such as this may help therapists to avoid inadvertently placing themselves in ethically compromising situations. It is important to consider the present findings in light of the study's limitations. First, although we were successful in obtaining a large, geographically diverse sample, individuals self-selected to participate in the study. Thus, it is possible that those who decided to respond to the survey differ systematically from those who did not. Similarly, because our survey was distributed primarily to $\mathrm{PhD}$ programs, resulting in proportionality fewer PsyD respondents, it is unclear whether the current findings generalize to the broader population of students in PsyD programs. Second, although participants responded to open-ended questions in regard to the reasons in general for conducting client searches online, we did not ask about motivations for any particular searches. Thus, we do not know how often searches were conducted for relatively harmless reasons (e.g., to obtain basic contact information) or for more ethically questionable purposes (e.g., curiosity about a client's personal life). Future studies should examine this important question. Finally, the present findings represent a "snap shot" of opinions and Internet behaviors at the point of data collection. However, the Internet is rapidly evolving, which includes the continual advent of new applications and features (e.g., Twitter, Foursquare) with potential relevance to training and clinical practice. It is safe to assume that therapists' attitudes and behaviors in regard to the role of the Internet in these domains will continue to evolve as well.
The acceptability of conducting searches for client information online is but one of the many complicated issues confronting therapists in a rapidly changing Internet environment. Findings from this study, particularly the incongruence between attitudes about searching and frequency of actual search behaviors, suggest a pressing need for this issue to be addressed within doctoral training programs. To facilitate this process, we offer the following recommendations:

1. Programs should establish policies governing student therapists' use of the Internet to seek information about clients, including the circumstances, if any, in which it may be appropriate to conduct such searches. In general, we recommend proscriptions against these behaviors except where it is likely to benefit the client and prior consent (preferably written) is obtained. There may be exceptions to this general rule, however, such as in certain forensic cases or situations when the therapist, client, or another individual is in imminent danger.

2. Policies governing therapists searching for clients (as well as other online contact) should be discussed with clients and spelled out in understandable terms as a part of the informed consent process at the outset of therapy. Therapists who desire to search for information about a client online should seek permission from the client to do so. Just as clients sign releases of information granting therapists permission to seek information from third parties, so too should written permission be obtained for therapists to seek information about clients online. This process should include a discussion of the risks (e.g., breaches of privacy) and inform clients of any exceptions to the need for informed consent.

3. To promote understanding of program policies, faculty and supervisors should discuss with students the ethical and therapeutic implications of conducting online searches. Until such time as more formal guidance is offered from APA, particular emphasis should be placed on the relevant principles in the existing Ethics Code along with heuristic models such as Clinton et al. (2010). Clinical supervision is an ideal context in which to have these discussions. While guiding students through a decision making process, supervisors can help them consider important therapeutic issues ("What is your motivation for searching?" "Will this information benefit your client?" "What will you do with the information?").

Additional research is needed to shed further light on trainees' searching activities. For example, it will be important to examine clients' perceptions of therapists' searching behaviors. Although many clients may experience uninformed searches as an invasion of privacy, others may be comfortable with certain online interactions with therapists. Anecdotally, we have heard of clients reaching out to therapists through Facebook and other sites. In contrast to the unilateral searches investigated here, these activities involve mutual interaction between therapist and client that raise a range of concerns about multiple relationships and boundary violations. Nevertheless, additional work is needed to explore whether there are any circumstances under which these 
types of interactions are permissible (e.g., a therapist "friending" an adolescent client to observe and help monitor online activities). Relatedly, an important focus of future research should be the converse of this study - that is, how often are clients searching for therapists online, and how does the information they obtain impact clinical practice? Considering the frequency of online activities, we assume that graduate student therapists are actively posting personal information on the Web, but it is currently unknown whether they consider the information they are posting in light of their roles as developing clinicians and professionals (Lehavot, 2009). The relevance of this issue is highlighted by recent findings that the majority of medical students and residents are active Facebook users and of those posting photographs, $70 \%$ of the photos included use (and in some cases excessive use) of alcohol, which could be considered unprofessional (Thompson et al., 2008). These results again underscore the need for students to receive guidance on the ethical, professional, and privacy implications associated with Internet usage.

References

American Psychological Association. (2002). Ethical principles of psychologists and code of conduct. American Psychologist 57: 1,0601,073. DOI:10.1037/0003-066X.57.12.1060.PMid:12613157.
Behnke, S. (2008). Ethics in the age of the Internet. Monitor on Psychology: 39(7): 74

Behnke, S. (2010). The Internet's ethical challenges. Monitor on Psychology 41(7): 32.

Clinton, B.K., B.C. Silverman, and D.H. Brendel (2010). Patient-targeted Googling: the ethics of searching online for patient information. Harvard Review of Psychiatry 18: 103-112. DOI: 10.3109/ 10673221003683861.PMid:20235775

Farber, B.A. (2003). Patient self-disclosure: a review of the research. Journal of Clinical Psychology: In Session 55: 589-600.

Fisher, C.B. (2002). A goodness-of-fit ethic of informed consent. Urban Law Journal 30: 159-171.

Fisher, C.B., and M. Oransky (2008). Informed consent to psychotherapy: Protecting the dignity and respecting the autonomy of patients. Journal of Clinical Psychology: In Session 64: 576-588.

Jones, S. (2002). The Internet Goes to College: How Students Are Living in the Future with Today's Technology. Washington, D.C.: Pew Internet and American Life Project.

Lehavot, K. (2009). "MySpace" or yours? The ethical dilemma of graduate students' personal lives on the Internet. Ethics \& Behavior 19: 129-141. DOI:10.1080/10508420902772728

Smith-Bell, M., and W.J. Winslade (1999). Privacy, confidentiality, and privilege in psychotherapeutic relationships. In: D.N. Bersoff (editor), Ethical Conflicts in Psychology (2nd ed., pp. 151-155). Washington, D.C.: American Psychological Association.

Thompson, L.A., K. Dawson, R. Ferdig, E.W. Black, J. Boyer, J. Couffs, and N. Black (2008). The intersection of online social networking with medical professionalism. Journal of General Internal Medicine 23: 954-957. DOI:10.1007/s11606-008-0538-8 